\title{
SUCCESSFUL CHILD PSYCHOTHERAPY OF ATTENTION DEFICIT/HYPERACTIVE DISORDER: AN AGITATED DEPRESSION EXPLANATION
}

\author{
Burton Norman Seitler
}

\begin{abstract}
Science tries to explain phenomena in ways that are demonstrable and replicable to develop logical, coherent, parsimonious, and predictive theoretical systems. Yet hyperactive children are given stimulants to "calm" them down, despite the fact that science would predict stimulants would increase hyperactivity. Bradley $(1937,1950)$ observed that half of the behaviorproblem children to whom he administered a stimulant for one week became subdued. He called this finding paradoxical, speculating that inhibitory centers of the central nervous system were stimulated. While Bradley's assertion of a paradoxical reverse effect in children may be an empirical observation, it is not an explanation. The Attention Deficit/Hyperactive Disorder (ADHD) is inferred to exist from hyperactive behavior, which in turn, is inferred to be neurological in origin, a circular argument. An inevitable consequence of the belief in the hypothetical neurological etiology of ADHD is that children are typically given stimulants. Using the case of a seven-year old child, described as experiencing ADHD, who was treated successfully without medication as an illustration, the author provides an alternative, more parsimonious explanation of the etiology, suggesting that ADHD is related to agitated depression.
\end{abstract}

KEY WORDS: Attention Deficit/Hyperactive Disorder; Agitated Depression/Sadness; Child Psychotherapy of ADHD.

DOI:10.1057/ajp.2008.25

\section{WHAT IS THE ETIOLOGY OF HYPERACTIVITY IN CHILDREN?}

Science persistently looks for explanations that can be demonstrated and repeated in order to develop logical, coherent, parsimonious, and predictive theoretical systems. Yet, when we look at children who exhibit hyperactive

Burton Norman Seitler, Ph.D., is a psychoanalyst/clinical psychologist in private practice. Director of Counseling And Psychotherapy Services-R (C.A.P.S-R), Ridgewood and Oakland, New Jersey. Faculty, Director of the Child and Adolescent Psychotherapy Studies Program, New Jersey Institute for Psychoanalysis and Psychotherapy (NJI), Teaneck, New Jersey.

Address correspondence to Burton Norman Seitler, PhD, 10 Wilsey Square (PH), Ridgewood, NJ 07450; e-mail: binsightfl@aol.com

This paper is a modified version of a presentation given by this author on March 12, 2006 for the New Jersey Institute for Training in Psychoanalysis, in Teaneck, N.J., entitled "Attention Deficit Hyperactive Disorder (ADHD): Successful Treatment of a Seven-year old Boy Diagnosed with ADHD, Without the Use of Medication." 
behavior and who are treated with biochemical stimulants, we see a notable exception to what good science would ordinarily lead us to expect. That is, science would predict that a child, whose behavior is already hyperactive, would become even more active if given a stimulant, like Ritalin or Adderal. Yet, many researchers have consistently shown that the opposite occurs.

Bradley first commented on this $(1937,1950)$ after administering Benzedrine and Dexedrine to children. Bradley treated 30 children, described as exhibiting behavior problems, who were sent to the equivalent of what we might today call a residential treatment center. After administering Benzedrine to the children for one week, Bradley (1937) concluded that there was "a spectacular improvement in school performance in 14 of the children" (p. 584). In addition, 15 of the children were "distinctly subdued in their emotional responses" (p. 579). Commenting on the nature of the drug and its presumed action in children as opposed to adults, Bradley stated:

A drug whose action is that of a stimulant may naturally be expected to produce changes in motor activity. In children, however, it is extremely difficult to measure motor activity per se apart from the individual's general behavior as shown by his mood and his intellectual activity. (p. 580)

He then adds the following observational remark:

It appears paradoxical [italics mine] that a drug known to be a stimulant should produce subdued behavior in half of the children. (p. 582)

This, almost incidental use of the term "paradoxical" has stood as the defining explanation (as opposed to mere observation) for why some hyperactive children respond to a stimulant by becoming "subdued." It does not raise questions why this would happen in children, nor can it explain the current claim that stimulants achieve the same "paradoxical" reverse effect in adults said to exhibit so-called adult Attention Deficit/Hyperactive Disorder (ADHD).

Since that time, the so-called paradoxical effect has become the singular sustaining rationale that has been repeatedly invoked as a justification for the use of stimulant drugs with ADHD children. While Bradley's assertion of a reverse effect may be an empirical observation on his part, it is not an explanation. Nor should it be regarded as one. He stated that a reverse reaction occurred, and called this reaction "paradoxical" because it was not what he expected in terms of how people usually react to a stimulant, but he failed to explain why this "reverse effect" occurred in the first place, speculating only that higher levels of the central nervous system which are involved in inhibition may have been stimulated. 


\section{SEITLER}

Since that time, the paradoxical effect, as it has come to be known, has been invoked automatically, without a second thought, as if it were an accepted, well-demonstrated explanation, rather than an interesting, even puzzling, contradictory, and thus exceptional finding. By raising an observation (even a potentially important one with profound implications) to the level of final explanation, further examination of the phenomenon being examined is barred prematurely. So too are questions inhibited that would ordinarily follow such a rather curious observation like the so-called "paradoxical effect." It seems curious that no follow-up questions regarding this particularly interesting observation have either been published, or given as much weight as the quasi-explanation noted above for this phenomenon. I believe that questions regarding the reasons for the paradoxical effect are more than worthy of our attention, they are essential. Accordingly, further on in this paper, I intend to offer an alternative explanation of this phenomenon.

At the same time, there has been a ready and relatively rapid acceptance-without further critical analysis — of the notion that the hyperactivity in question must be neurological in origin. This notion has been held onto doggedly in certain circles right up to the present time. Thus, what we now often refer to as "Attention Deficit Disorder, with or without Hyperactivity" (ADD, or ADHD) was thought to be neurological in origin without solid evidence to support this position. Whenever its basis was questioned, new terminology emerged. So, after using the phrase "minimal brain damage," "minimal brain dysfunction" was substituted. This persisted for some time. After it no longer appeared to convince, "minimal cerebral dysfunction" was invented, followed by "minor cerebral dysfunction," or "minimal cerebral insult." Although no "hard" neurological signs were ever found (e.g., lesions, tumors, malformations, diseases, and so forth), the idea that "there must be a neurological component in there somewhere" persisted. Even when neurological-sounding names were eventually changed giving a more behavioral appearance, the implicit notion was still that faulty brain mechanisms, possibly acting in concert with chemical imbalances were the culprits. Reflecting this expanded view, more name changes took place. "Hyperkinesis" soon stepped aside in favor of "hyperactivity," which was then followed by "attention deficit disorder," which was later modified to provide an option for the inclusion or omission of hyperactivity. The latest slant on the subject, "Executive Functioning Deficit" (Fried, 2006), adds yet another name to the mix.

It is not hard to see that the central neurological leaning is still with us as an explanation for hyperactive behavior, leaving open the door to further pairings with its cousin, the chemical imbalance theory, this despite the 
fact that neither assumption has ever been precisely defined, reliably measured, or conclusively demonstrated.

At present, the Diagnostic And Statistical Manual IV (DSM IV, 1994) characterizes ADHD as including attentional problems, restlessness and fidgety behavior, increased mood liability, low frustration tolerance, low self-esteem, difficulty sticking with a task, and problems with group situations which are made particularly effortful when sustained attention is required. Even though an old term was replaced by a new one each time, no greater explanatory power was ever provided. Rather, it seemed that many remained stuck with the hypothetical neurological etiological explanation for hyperactivity. As was pointed out in a recent paper:

This etiological explanation has held sway despite the fact that no solid evidentiary basis, other than a purely theoretical one, has ever been pro- vided to bolster the neurological etiology hypothesis. The argument therefore became circular, in which ADD was inferred to exist from hyperactive behavior, which in turn, was inferred to be neurological in origin. (Seitler, 2006, p. 230)

Of even greater consequence, faith in the neurological hypothesis inevitably resulted in an organic approach to treatment for youngsters who were diagnosed with this disorder. As a result, children who were diagnosed with ADHD or any of its previously utilized names typically were given stimulant drugs. If questions were raised regarding the rationale for using stimulants for youngsters who already appeared to be excessively stimulated, the classical response was invariably invoked that the medications worked in a "paradoxical" manner vis-à-vis Bradley's earlier remarks (1937, 1950). That is, they supposedly worked in reverse. To date, a sufficiently comprehensive explanation for the so-called "paradoxical" reverse effect has not been satisfactorily presented.

Although different studies have produced different results, there is curious agreement that significantly more boys have been diagnosed with ADHD than girls. Contingent on which study one accepts, the ratio of boys diagnosed, as compared with girls, ranges from 3:1 in community samples (Arnold, 1996) to 10:1 in clinic-referred samples (Gaub and Carlson, 1997). The DSM IV claims that ADHD occurs in boys 4-9 times more frequently than in girls. So, if a straightforward neurological explanation were sufficient, we would logically expect that the amount of neurological problems associated with ADHD would be no greater in boys than in girls. Hence, the present neurological explanation as it is presently constituted, lacks sufficient complexity or depth to make sense out of this substantial lack of equivalence between the two groups. Because of this, there are some who have asserted that ADD and ADHD do not even exist, that they are really 
clusters of behaviors representing a syndrome, as opposed to an actual separate diagnostic category on its own (Baughman, 1993; Breggin, 1994,1995). Kaye (1994) thoughtfully takes a middle of the road position by raising the possibility that ADD may constitute a co-morbid condition, rather than a singular entity of its own. Assumption of the co-morbidity proposition has its own share of problems. If the "hyperactivity" in question is assumed to be an "organic condition," and the automatic response is to treat this so-called organic condition with stimulant drugs, then it must follow that the presence of other co-morbid "conditions" would have to be treated that way as well.

\section{AN ALTERNATIVE EXPLANATION FOR THE "PARADOXICAL EFFECT" AND ADHD}

For nearly 40 years, I have worked with children in residential treatment settings, mental health centers, in the public school system sector, and in private practice. I have noticed on a consistent basis that there is one thing in particular, which children who seem to be experiencing ADHD, exhibit. The one thing that they have in common is that profound feelings of sadness frequently manifest themselves at some point in the treatment. At first, the sadness is not obvious on the surface, but in the course of treatment it is regularly discovered. So often has it manifested itself in my experience with these children, that I cannot consider the sadness as merely inconsequential or coincidental. On the contrary, as I have said elsewhere: ... it leads me to believe that the sadness is an integral underlying component of the condition currently referred to as ADD (Seitler, 2006, p. 231).

Coles (1987) arrived at a similar conclusion. Along the same lines, Campbell (1982), in an attempt to localize the feelings of sadness that she too felt were part of the phenomena known as ADD, speculated that there might be a greater propensity to use the right side of the brain because of feelings of sadness. So, if there were indeed a neurological component in ADD, it would appear to be precipitated and/or stimulated by a particular affect, one that is associated with depression. In the latter regard, McConville (1972) estimated that between 50 and $60 \%$ of children who are referred to mental health clinics for psychotherapy show symptoms of depression. McConville intimated that much of what is called ADD or various other kinds of conduct disorders might in fact, be forms of "masked depression."

\section{AGITATION AS A DEFENSE AGAINST DEPRESSION}

These findings coincide with my own observations that have been accumulated and crystallized over many years. It is my position that in many, 
if not most cases, ADD represents a form of what I prefer to call "agitated depression." This would explain to a large extent why there seems to be such a disproportionate number of boys who show signs of ADD with hyperactivity, as opposed to girls. I believe that the reason for this may be contextual. I suspect that this finding in which the incidence of boys exhibiting signs of ADD significantly outnumber girls, may be related to the fact that in our culture the manner in which depression is expressed differs between males and females.

\section{CULTURAL CONTEXTS INFLUENCING BEHAVIORAL ACTIVATION}

Males, by my observation in my practice, when faced with feelings of defeat, helplessness, hopelessness, loneliness, sadness, etc., often become aggressive, and frequently run from their internally upset state. In other words, such males are merely attempting to handle the pain of depression by a series of avoidances, involving the adoption of an action-orientation. By not "sitting still," so to speak, they momentarily stave off the ravages of the depression. Of course, as we know, when we try to avoid something that is internal, "it" inexorably circles back on us in the end. Thus, the very behavior which is cleverly designed by the unconscious to protect the self against the feeling of depression becomes so unwieldy that it stirs up the ire of others who react with castigations, remonstrations, and punitive counter-actions of their own, which ultimately completes the pathological circle and culminates in the individual feeling depressed (all over again).

Female patients I observed tend to cry and to overtly express their inner distress. Not so curiously, when males are able to express their sadness directly, without excessive shame, guilt, or the threat and/or actuality of retaliation, there is less of a tendency to act out their depression. This is what I have observed when I have treated such individuals in psychotherapy. That being the case, it would follow that the need for stimulant medications would not have to be a necessary component for treating each and every case of ADD/ADHD.

\section{THE CASE OF A SEVEN-YEAR-OLD BOY}

The following is an illustration of a young boy who was referred because of ADD with hyperactivity, who was treated successfully in psychoanalytically oriented psychotherapy without medication. This case is offered as just one example of a host of individuals who had been independently diagnosed as exhibiting ADD/ADHD that I have treated over the years with consistent success without the use of medication. 
At the time that I first saw Art, he was a seven-year-old youngster, who was brought in by his parents for psychotherapy because he was experiencing a great deal of difficulty focusing in class, paying attention to his teachers, and in particular, heeding his parents. His parents described Art as "hyperactive, prone to outbursts and temper tantrums, and generally difficult to manage." He was the embodiment of Ricochet Rabbit, Dennis The Menace, and Pinocchio rolled into one. The parents had taken him for numerous examinations in an effort to determine some sort of basis for his behavioral problems. A psychiatric examination performed one year prior to his entering therapy resulted in a diagnosis of "Attention Deficit Disorder with Hyperactivity (ADHD)," for which medication (i.e., Ritalin) was prescribed by the examining psychiatrist.

The father of Art's mother was an alcoholic. She had been in a themecentered group for two years with a therapist who specialized in the treatment of adult children of alcoholics. Despite being well meaning and conscientious, she appeared to be very tense, high strung, and apprehensive about new things or change. She described herself as very religious, as being a perfectionist, and as seeing things in simple black and white terms. As an adjunct to Art's treatment, his mother had been seen by me on a twice a month basis. She often seemed to be highly reactive, almost to the point of being catastrophic whenever she perceived a situation as even remotely fraught with danger. At such moments, she usually sought immediate relief and would quickly phone me; usually it seemed, for some sort of "magical" advice. I regarded these calls as instances of transference responses to me, or possibly a life-long effort on her part to obtain needed nurturing and protective responsiveness. I can only speculate as to the consistent availability of significant loving figures in her life when she was growing up. As a child, she recalled being a striver. She was an accomplished ice skater and hoped one day to compete in the Olympics. Unfortunately, she suffered an accident and her potentially bright career, which she had begun at age 5, came crashing to an abrupt halt at the tender age of 13. While she described her father as an unrelenting and demanding taskmaster, who was rarely satisfied with her practices and subsequent performance, she explained that his verbal criticisms and general harshness when she was skating were still considerably more tolerable than the many other times, when he came home drunk and was physically abusive to her. Moreover, she added whenever she skated well she would receive accolades from others (her coach, friends, etc.). She said that one compliment could sustain her for weeks at a time. When this was not in the offing, she experienced considerable anxiety mixed with bouts of depression. I suspect that the upsurge of such feelings may have been what she was experiencing whenever she felt impelled to call me frantically. 
Most of the time, she said that she blamed herself for her father's behavior, often saying to herself that she must not have done something right. She described her mother as being a long-suffering woman who doted on her husband's every wish and whim. However, when she felt most scared or alone, she did not feel that she could turn to her mother. She said that her mother was generally passive and withdrawn and unable to stand up for herself, much less care for her. Shortly after Art's mother's promising skating career ended because of her accident, she experienced another tragic turn of circumstances. Her mother suddenly died of a stroke. This too, Art's mother reported that she blamed on herself when she was a child.

Art's father was described as a successful businessman. He gave the appearance of a low-keyed, gentle, tolerant individual, who seemed to understand his wife and to be very supportive of her. Unfortunately, he was often away on business trips. And, even though he attempted to take his wife and his family with him on many of his trips, he was not always able to do so. He indicated that he saw himself as a kind of mediator between his wife and their two boys. He shared that he often felt that he had to be the one who was "levelheaded." This was similar to the way he had to be as a child, where he was the one in his family who had to see things clearly so that things could be accomplished in what he described as an otherwise "chaotic family." He related that he was the middle child of three in a family that was "in constant turmoil." He wondered whether being the middle child afforded him the opportunity to be overlooked and thus remain safe from the ravages of his family's persistent fighting. At the same time, he also was curious if he may have missed out on some of the things his older and younger brothers received because of their demanding, albeit attention-getting disruptiveness.

Art was the younger of two boys. His older brother was 23 months his senior. Art was a planned child. Pregnancy was reported to have been uneventful. Labor, however, was particularly long, but his birth, delivery, and Apgar scores were characterized as being within normal limits. His mother attempted to breast-feed him, but was unsuccessful, reportedly because Art "kept squirming and was unable to fix upon the breast," in his mother's words. She indicated that she experienced a great deal of tension when "Art did not quickly take to the breast." He developed colic, which lasted for several months. He did not sleep through the night until he was almost six months old. Even then, he would often shriek in the middle of the night, which would then wake up his mother. She in turn, became very agitated and impatient. Sometimes, she would scream back at Art. It seemed as if the only way he could return to sleep was for his parents to bring him into their bed. He would then fall asleep. However, the instant he was returned to his bed, he would resume what his parents described as "shrill, 
piercing cries." His distress became theirs, as did their helplessness and inability to soothe him became his. No food fads or eating problems were noted. Sitting up, crawling, and talking all were reported to have occurred within normal limits. Toilet training was begun at age 1 and was not successfully completed until age $31 / 2$. His mother felt that he was "stubborn, had a mind of his own," implying that it was a power struggle.

\section{COURSE OF TREATMENT}

Art appeared to be a slender, brown-haired youngster with a fair complexion, and pleasant disposition that ranged from being very serious (and almost somber in nature) to being very chatty and goal-directed. We met on a twice per week basis, and I saw his mother twice per month. His intellectual functioning was estimated to be within the Average range. Often, Art's thinking was observed to be somewhat concrete. Along with this, some rigidity was seen. Reversals in cause and effect as well as magical thinking were also noted.

Although Art was receiving Ritalin for his ADHD condition, I asked his parents that on those days when he came to my office, not to give him his usual regimen of medication until well after the appointment had ended. My rationale for the removal of medication on days when Art met with me was to eliminate, or at least reduce the possibility of the medication serving to mask any possible underlying feelings on Art's part that might have been associated with his behavioral outbursts. I hoped that in so doing, Art's real feelings could fully emerge in an undisguised, undefended against, unbridled form, thus allowing us to see them in the consulting room, and rendering them more directly amenable to treatment. He was seen twice a week for three years.

When Art's mother first brought him into my office, it appeared as if she had a great deal of difficulty separating from him, despite the fact that he quickly and easily struck up a rapport and engaged in a play activity with me. Noting the work of Berta Bornstein (1948), it seemed to me that Art was able to develop what she referred to as "distancing identification," which ultimately permits the child to move beyond earlier Oedipal issues. Separation anxiety that might be expected in early latency, according to Bornstein, did not appear to be evident at first glance with Art. Rather, it was Art's mother who seemed to be experiencing some semblance of separation anxiety. Either this was exclusively her own issue, or it was subtlety being transmitted to her by Art (or possibly a combination of the two). On the other side of the coin, one can argue that it was Art's mother who might have been transmitting implicit signals to him, rather than vice versa, signals which may be quite different than her explicit messages to him to "control 
yourself," ."don't act out," and "don't be so impulsive." Drawing from classical psychoanalytic explanations, Johnson and Szurek (1952) observed that parents may sometimes experience "vicarious gratification of their own poorly integrated forbidden impulses in the acting out of the child through their unconscious permissiveness or inconsistency [italics is mine] toward the child in the spheres of behavior." When healthy attitudes are conveyed to the child by the parent(s), this provides him with the ability "to anticipate: that his basic impulses are gratifiable, at least eventually; that his disappointment, rage, or revengefulness at delays to his satisfactions are understood and accepted as natural reactions, but that their form of expression may invite retaliation from others, and that the parent will patiently respect such reactive feelings, prolonged though they may be" (p. 326). The authors further state that "such neurotic needs of the parent exist either because of some current inability to satisfy them in the world of adults, or because of the stunting experiences in the parent's own childhood" (p. 327). A more current viewpoint (Gabbard, 2005; Winer, 1993; Vaillant, 1993; Wallace, 1992; and Brandell, 1992) is that Art's parents had great difficulty integrating, regulating, and modulating their own affects, and thus, were unable to help Art with his own unbridled affective distress.

At various times, we observed that Art's mother tended to guess at what he may have been feeling and then to tell him what she thought, rather than ask him. It seemed as if this greatly influenced him, possibly overriding his own feelings and thoughts, and thus creating a separate reality for Art. For example, I am reminded of one particular occasion when Art was entering the waiting room, just before coming into my office. At that moment, Art's mother apparently overheard him saying something involving content containing a mildly aggressive theme. She quickly interjected by telling him "you don't really feel that way," and somehow or other converted Art's feelings into something other than what he had, in fact been verbalizing. Similarly, during our initial sessions, Art carefully made a point of explaining to me that certain words were "bad" and should not be used. When asked about this, he said people should not say words like "mad." because "only dogs get mad." So, if words which have an aggressive component or some other parentally unacceptable emotions are "bad" and cannot be uttered, how else can a child express such feelings? One need not wonder too long on this question. In this instance, Art's choices were as clear as they were limited. Art was faced with having to keep his feelings inside. In his mind, there were no other solutions that his environment afforded him. Anger was not to be channeled. It was to be disavowed. It must not exist, much less be diverted or sublimated. Failing to do so would result in Art's being rebuked, reproached, rebuffed, and rejected. His angry feelings kept inside became angry feelings turned against the self. His 
reasoning took a concrete, black and white, all or nothing form of the following type: "my thoughts and feelings are bad, therefore, I am bad," a formula for depression. At the same time, keeping such feelings pent up inside created considerable tension and inner agitation. So, despite the fact that Art was able to be highly verbal, when this channel was blocked by important figures in his life, his only option was to keep his feelings in. The problem was, the longer he did this, the more the build up of his inner distress, until he could no longer contain his feelings. At such a point, his feelings emerged with the force of a volcano that had been misguidedly capped, in the form of unmodulated affect, raw impulses, unregulated actions, and behavioral outbursts. Thus, he replaced conversation with action, doing instead of talking, reacting as opposed to simply being.

My work with Art initially consisted of starting with, and utilizing Art's own action-orientation on his behalf. In a kind of version of "if you can't beat 'em, join 'em," my early work with Art was highly active and motoric in nature. We played catch with a nerf ball; we shot baskets with a rolled up sock and a hanger rounded out into the shape of a hoop that was suspended over the edge of a door; and we built fortresses made of pillows from the couch. But, it should be pointed out, simply venting the inner tension-producing feelings, while necessary, is insufficient. Words, heretofore tainted by parental prohibitions, needed to be provided. These words were to be coupled with the activity in which we were involved. But the words needed to be of such a nature that they could slip by the internalized parental reproaches, while at the same time being capable of releasing Art's highly pent-up emotions. In addition, I had to find the proper metaphors that correctly depicted Art's feelings without telling him that "this is what you are feeling," as his mother had done. What I ultimately chose to do was depict my own feelings about particular activities, games or events that we were sharing together, making it very clear that these were my feelings, and that they did not necessarily mean that the way I felt is the way everybody else feels or that the way I felt was the only "normal" way of feeling. In so doing, I allowed room for Art to separate and individuate, while simultaneously modeling for him words that express feelings that are generally acceptable in most circumstances. At several points, when Art and I were having a catch, he severely chastised himself verbally if he dropped the nerf ball, or threw it wildly. For example, he frequently said, "I'm such an idiot. What a jerk. I can't even catch a stupid ball. Stupid!" When I did not catch the ball, my verbalizations consisted of much more forgiving sentiments, yet ones that expressed my frustration as well. For instance, I would say something like "I feel so awful I when I miss;" or "I try so hard to catch the ball and it just irks me when I don't;" or "man, I just feel so upset about dropping that." This allows room for an eventual 
discussion of what "awful," or "irked," or "upset" feels like. It says that words help with the expression of feelings. Moreover, it provides examples of acceptable words that can be used to get feelings out, without rebuke.

Eventually, Art expressed interest in a number of the board games that were available in the office. Accordingly, he was given the opportunity to play and talk. After a fashion, he was able to maintain his focus on any game that he chose to play for the entire duration of the game. He tended to stick very closely to the rules of the game(s) that he had chosen and rarely deviated. Art's participation in the games often was very intense, yet, except for the early stages of treatment, his level of motoric activity was not excessive. In fact, as treatment progressed, Art's motoric activity diminished substantially to the point of being non-remarkable. Nevertheless, Art sometimes regressed from time to time. At such moments, his voice changed to a higher pitch, and took on a kind of singsong, "baby-talk" quality. Usually, this happened when our conversations hit on something that was stress-producing for him, such as when he talked about a particular youngster in his class who he felt teased him, or when he spoke of situations in which he felt left out, or occasions when he felt misunderstood. One incident bothered Art so much that he turned to his mother for support. This was due to his perception that his teacher had picked on him and embarrassed him in class. Upon learning of this, Art's mother impulsively rushed to the school and bitterly complained to the principal about the teacher (but never directly spoke to the teacher herself). Shortly thereafter, she attempted to pull Art out of the school and transfer him to another school. Art was able to say that he actually liked the teacher, that he had begun to make friends, and that he did not want to go anywhere else. Despite this, his mother was insistent on making the change. She was so strident at one point that she tried to enlist me to "use your psychology on Art to convince him to make the change in schools." From this, it seems to be clear that Art needed to be listened to and heard, without necessarily being (over-) reacted to.

Once Art's "hyperactivity" had quieted down during the course of his treatment, the "hyper-reactivity" of others close to him became more evident. This lead me to wonder if Art's so-called ADD in effect, had previously acted as a camouflage for the excessive reactive behavior of important caretakers in his life. From this, we can understand better what Art's mother may have been going through when she heard her son shrieking in the middle of the night and why she found herself yelling back, possibly out of her own helplessness and consequent impotent rage. And, in understanding her pain, I was in a better position to help her learn to self-soothe, and to help her pass this along to Art. In some ways, in her zealous attempt 
to protect Art (probably from her own painful reminiscences of her own childhood), Art's mother may have unwittingly fostered a schism within Art between his authentic self and her vision of whom he represented to her. In the latter regard, there seems to have been a repetition of earlier childhood events of Art's mother along with Art himself that somehow got enmeshed. Because the boundary between self and son became blurred, Art's mother reacted as if she felt exactly what he was going through. If he cut himself, she felt as if she was the one that was bleeding. His mother's symbiotic-like tie (Mahler, 1972) hindered Art's separation and individuation process. While this may explain Art's reluctance to leave one school and transfer to another, I suspect that attempting to stay at the first school was a sign of assertion, separation, and independence on Art's part, as much as it was an attempt to maintain sameness, constancy, and a sense of continuity with the school, his teacher, and his new found friends. In the latter regard, the notion of maintaining important objects seemed to have been played out symbolically by Art with me in one of our games together.

For example, when playing "Uno" with me (a game whose object is to see which player can get rid of all of his playing cards first), Art purposely attempted to collect as many cards as he could. If interpreted in a Kleinian sense, this might be seen as a form of depressive anxiety, in which Art may view his feelings as intolerable to his mother and which might destroy her (both as an internal, as well as an external object). In other words, if the "Uno" cards somehow symbolized his mother or his tie to her, then even the loss of one card might be intolerable to him.

On another occasion, after Art had lost a different game that we were playing, he became visibly upset. When asked about this, he insightfully summed up his feeling that "losing means you are a loser!" This too, seems to illuminate the issue of early object loss in his life and how Art's thinking personalized such events as self-rebuke in the form of "when bad things happen they are somehow my fault." And, although cards or game materials are not necessarily the same as important psychological objects, they may bear a symbolic equivalence, as Melanie Klein observed (1952), or at least may be representative of transitional objects that stand in place of important figures. At the same time, these "game objects," also undoubtedly symbolized aspects of the therapeutic transference. As such, Art may have expected to be chastised or abandoned by me. After all, if he sees himself as a "loser," because of his earlier presumed experiences of rejection associated with his mother's misattunement to his real inner feelings, it is not unreasonable to assume by extension, that he would respond transferentially to me by expecting me to cast him off, much like he may have envisioned his mother's reaction to him. When I inquired about this, Art responded by asking 
me why I would be any different? He then added, "my mother screams at me if I don't do my best, and my father is never around when I need him." Inquiring further, I asked whether he thought that I would leave him too? Hesitantly, he said that he did indeed think so. When asked about how this made him feel, he said, "I get very upset and nervous and want to run and go and go and go." Over the years, I have found this feeling of needing to run to be fairly typical of children who have been described as ADD/ADHD and it is one of the reasons I regard this "condition" to be related to an agitated form of depression.

Going further, Art's concern about his teacher embarrassing him may also have been reflective of difficulties in separation-individuation. As Schore (1991) cogently pointed out, often the functional onset of shame may be traced back to problems in separation-individuation, particularly during the time span ranging between the practicing phase through the early part of rapprochement. Schore intuitively observed that this typically occurs due to an eager anticipation on the part of the child for reunion with the mother, which is met with disappointment because of the unexpected misattunement on her part. Understandably, ego functions having to do with basic mood regulation and the related capacity for trust or mistrust, as well as the capacity for abstract reasoning or other forms of secondary process thinking may be effected negatively as part of this misattunement. Clearly, this would explain the array of moods that Art exhibited, ranging from chatty and light to very serious and somber, as well as the concrete thinking that Art manifested at times. Moreover, this throws additional light on Art's susceptibility to regress so rapidly.

After Art demonstrably began to calm down in the course of our work together, heightened parental reactivity became more visible. Art's mother reported to me, "I found myself feeling on edge all the time, often for no reason at all. Even though I knew Art's behavior was so much better, it was as if I expected the worst from him anyhow and I lay in wait for it to happen." To her credit, she began to be able to differentiate his behavior from her feelings. I believe that she was finally able to receive (and take in) something for herself in her work with her therapist and with me (even though my work with her was merely as an adjunct to her son's treatment). Coincidentally, the number of her calls to me, as well as their frantic, urgent quality dramatically subsided.

No longer could it be said that Art's previous hyperactive symptom picture was located solely within his neurological makeup. Nor could it be asserted that the "hyperactive" behavior was exclusively located within Art. After Art's parents saw improvement in his behavior, consisting of the near absence of his hyperactivity, working with their physician, they slowly 
reduced his Ritalin dosage; then the frequency of the Ritalin; finally weaning him off of it completely.

\section{FURTHER CONSIDERATIONS}

So, then, various questions must arise, such as, would Art have become "hyperactive" (that is-would he have exhibited hyperactive behavior) if he had been soothed? In the normal course of development, soothing occurs when the mother is available to the child and is in tune with the child's inner state and needs. Kohut (1977) points out that the child needs a responsive and empathic connection for psychological survival. He says, "the child's rudimentary psyche participates in the selfobject's highly developed psychic organization. This child experiences the feeling states of the selfobject-they are transmitted to the child via touch and tone of voice and perhaps other means-as if they were his own" (p. 86). However, if the mother is otherwise preoccupied, or herself unable to tolerate either her own anxiety, or the baby's (as seems to have been the case with Art's mother), the infant experiences this as a bad mommy/bad me and needs to split off from this unbearable feeling. Reparative soothing, if it is to come about, usually does so because of the transference that develops within the safe domain of the holding environment, in which the patient slowly starts to be able to relate to, internalize and be able to hold onto a good enough object (in the form of the idealized therapist) who is perceived and experienced as constant, reliable, and predictable. Had there been adequate attunement to Art's early needs, would he have learned to internalize such soothing and subsequently have been able to soothe himself? While it is not possible to answer this with certainty, Art's considerable growth in treatment strongly suggests that there are self-interactive regulatory issues at play. He learned to put inner process into words, to use words to express his feelings, and to act as the medium by which he had a greater possibility of having his needs met. Even when his words were overridden by external authority figures, he still expressed how this irked him, how this felt awful, or how it upset him when this occurred.

It is my contention that empathy and empathic responsiveness were the vital ingredients in this treatment. It was my feeling that for treatment to have been successful, Art needed to be able to express those feelings that were previously considered to be unacceptable and were therefore impermissible. However, the mere expression by itself of such feelings only would have acted to vent some of his inner turmoil. While this may have been beneficial in the short term, if one stops at that point, experiential insight, so necessary for long-term growth would not have developed. As far as I am concerned, an absolutely essential corollary to Art's being able to 
verbally express his feelings, was for me to be able to tolerate their expression, and to help Art to regulate them so that he too was able tolerate them without feeling excessive shame or humiliation.

In the course of treatment, Art was helped to observe his actions and what they produced. In short, our work together helped him develop a self-observing ego so that he could establish a modicum of insight into cause and effect. Instead of rebuking him for his impulses, I accepted them and helped translate them for Art in terms of his ego functions, and how necessary they were initially for him to survive. What he learned in our work was not that his behavior was terrible and he too was terrible, but that his behavior was important to him and was the only thing he knew how to do to get attention and to be heard. Unfortunately, it was negative attention. Regrettably, his actions camouflaged his wish to be heard, resulting instead, in his being misheard. What Art needed to learn was that his actions were not merely haphazard, but were intended to get noticed and be heard. When Art was able to observe his actions and notice the connection between what he was feeling and then how he acted, he was able to develop a modicum of insight into his way of being. From this, he was later able to find better ways of expressing his feelings, ways that would be accepted by his family or others in positions of authority.

Through the transference Art ultimately was able to reactivate many of his conflictual feelings and many of the conditions that may have given rise to, and fostered his self-fragmentation. Settlage (1977) observed that the continued healthy availability of the mother is crucial to the healthy resolution of developmental conflicts that may have arisen in the course of the rapprochement phase. He says that it is here that "the early sense of omnipotence and control that the child brings with him from the symbolic phase needs to be gradually replaced by the belief in, and enjoyment of his own rapidly developing ego capabilities," rather than having the "wind taken out of his sails" suddenly, arbitrarily, and overwhelmingly with ensuing feelings of deflation and humiliation. Settlage goes on to assert that, "a too sudden deflation of [one's] sense of omnipotence and control tends to evoke the grandiose view of the self and idealization of the omnipotent parent," in short, narcissistic defenses involving creation of a false self. Kohut (1977) refers to this as an expression of the "grandiose self," in which the individual engages in emotional and behavioral "expansiveness."

Thus, in a Winnicottian view (1951), it was imperative that the treatment became the "holding environment," and that the therapist became the "transitional object" allowing for reparation and the subsequent capacity for separation-individuation. There are special considerations, as Winnicott (1958) pointed out with regard to a latency-age child. For one thing, the latency-age child is presumed to have a relatively underdeveloped ego, 
in comparison with adults. As a result, they may not feel that their behavior or feelings are discordant, or for that matter, they may not behave as if they were ego-alien. Accordingly, not feeling as if "they are ill" they may not feel any great urgency to do anything about their present circumstance. Consequently, "they have no incentive to stay in analysis and no encouragement to go on with it" (Klein, 1932, in Winnicott, p. 118). Therefore, says Winnicott, it is important for the analyst to interpret things early on to the child. It is felt that by doing this, the child will become oriented to the analytic treatment, will have a better chance of experiencing relief (from problems he was not initially conscious of), thus increasing the probability of his seeing and appreciating the benefits of therapy. While many analysts believe that the transference and resistance phenomena are believed to occur in child patients, as well as in adults, one aspect of the analytic procedure does not seem to apply, namely the child's use of "free association." Despite the fact that children in general at this age have the intellectual capability for indulging in free association, they are often reluctant to do so, according to Bornstein (1948). Bornstein adds, this may happen because "free association is experienced by the child as a particular threat to his ego organization" (in Winnicott, 1958, p. 120).

If we look at the latency phase of development as a stage in which the child is beginning to manage affect to a greater degree than before, then it is conceivable that even the use of free association, an old mainstay of psychoanalysis, may risk taxing a presumably already overburdened self organization to the point of fragmentation, precisely at a time when the self is not fully developed to handle what would be tantamount to an onslaught of a multiplicity of stimuli.

Winnicott added that the right moment for early interpretation, as you might expect, is dictated by the material itself. That is, whenever the material is clear is when interpretation is admissible. Nonetheless, interpretations should be uncomplicated and fairly concise. As Winnicott stated, the accuracy of the interpretation may be of lesser concern to the child than the analyst's clear-cut intent to understand the child, identify with, and attempt to help him or her. This is the empathic glue which helps cement the relationship of the patient and analyst, while helping to bind the patient's ego fragments together. In this regard, my steady attempts at being empathic and identifying with Art's plight helped to establish me as a constant object for him, one that was not merged with him, and which did not need to submerge his authentic self so that I might live, but rather as one who accepted Art for who he was, in his entirety-the so-called "bad" right along with the "good."

It needs to be repeated for emphasis, that Art was not under the influence of medication during any of our sessions together. As the reader will 
recall, this was because I had instructed his parents to not give his usual regimen of medication until well after the appointment had ended on those days when he came to my office. Ritalin is considered to be short acting. By removing it, if only for our sessions, I felt that its influence on the sessions would be eliminated. In so doing, there would be less concern on my part as to whether the Ritalin was "masking" Art's feelings, fantasies, and overall behavior, and I would be in a better position to get a more accurate picture of how Art generally functioned. I then related to Art as a human being in need. I became a constant object for him, one that he could depend upon to accept him in his entirety without demonizing his feelings or considering them, or him as abnormal. I helped him observe his actions and what they produced. In short, our work together helped him develop a modicum of insight into cause and effect. Instead of rebuking him for his impulses, I provided him with an opportunity to express his feelings, and I gave him alternatives by which he could make his feelings known through words and conversation, rather than impulsive outbursts and action. From this, he would have the possibility to get many of his needs met. If any neurological changes did, in fact, take place, they were as a result of these measures, rather than any direct neurological and/or chemical interventions.

In conclusion, although Art is a unique individual in his own right, his case does not stand alone. It is not an exceptional case. It represents an example of most of the children that I have treated successfully without medication who exhibited behaviors referred to as ADD/ADHD.

\section{REFERENCES}

American Psychiatric Association (1994). Diagnostic and statistical manual of mental disorders, 4th edn. Washington, DC: American Psychiatric Association.

Arnold, L.E. (1996). "Sex differences in ADHD:" Conference summary. Journal of Abnormal Psychology, 24, 555-569.

Baughman, F.A. (1993). Treatment of attention-deficit disorder. JAMA, 269, 2368.

Bornstein, B. (1948). Emotional barriers in the understanding and treatment of young children. American Journal of Orthopsychiatry, 18, 691-697.

Bradley, C. (1937). The behavior of children receiving benzedrine. American Journal of Psychiatry, 94, 577-585.

Bradley, C. (1950). Benzedrine and dexedrine in the treatment of children's behavior disorders. Pediatrics, 5, 24-36.

Brandell, J. (1992) (Ed.), Countertransference in psychotherapy with children and adolescents. Northvale, NJ: Jason Aronson Publishing Company.

Breggin, P. (1994). The war against children. New York: St. Martin's Press.

Breggin, P. (1995). The hazards of treating "Attention Deficit/Hyperactivity Disorder' with methylphenidate (Ritalin). Journal of College Student Psychotherapy, 10(2) 55-72. 
Campbell, R. (1982). The lateralization of emotion: A critical review. International Journal of Psychoanalysis, 17, 211-229.

Coles, G. (1987). The learning disabilities test battery: Empirical and social issues. Harvard Educational Review, 48, 3113-3340.

Fried, R. (2006). Defining executive function deficits in ADHD. Paper presented to the American Psychiatric Association, Sunday, May 21: Advances in the Neurobiology and Thearpeuctics of ADHD (Supported by Cephalon Pharmaceuticals, Inc.).

Gabbard, G. (2005). Psychodynamic psychiatry in clinical practice, 4th edn. Arlington, VA: American Psychiatric Publications.

Gaub, M. \& Carlson, C.L. (1997). Gender differences in ADHD: A meta-analysis and critical review. Journal of the American Academy of Child and Adolescent Psychiatry, 36, 1036-1045.

Johnson, A. \& Szurek, A. (1952). The genesis of antisocial acting out in children and adults. Psychoanalytic Quarterly, 21, 323-343.

Kaye, S. (1994). The place of depression in dysfunctional learning. Psychoanalytic Psychology, 11(2), 265-274.

Klein, M. (1932). The psycho-analysis of children. London: Hogarth Press.

Klein, M. (1952). The origins of transference. International Journal of Psychoanalysis, 33, 433-438.

Kohut, H. (1977). The restoration of the self. New York: International Universities Press.

Mahler, M. (1972). On the first three subphases of the separation-individuation process. International Journal of Psychoanalysis, 53, 333-338.

McConville, B. (1972). Depression and suicide in children and adolescents. In P. Steinhauser \& Q. Rac-Grant (Eds.) Psychological Problems of the Child in the Family. New York: Basic Books.

Schore, D. (1991). Early superego development: the emergence of shame and narcissistic affect regulation in the practicing period. Psychoanalysis and Contemporary Thought, 14(3), 188-250.

Seitler, B.N. (2006). On the implications and consequences of a neurobiochemical etiological of Attention Deficit Disorder (ADHD). Ethical Human Psychology and Psychiatry, 8(3), 229-240.

Settlage, C. (1977). The psychoanalytic understanding of narcissistic and borderline personality disorder: advances in developmental theory. JAPA, 25, 805-833.

Vaillant, G. (1993). The wisdom of the ego. Cambridge, MA: Harvard University Press.

Wallace, B. (1992) (Ed.), The chemically dependent: Phases of treatment. Bristol, PA: Taylor \& Francis Publishers.

Winer, J. (1993). The annual of psychoanalysis. Vol. XXI. Hillsdale, NJ: Analytic Press.

Winnicott, D. (1951). Transition objects and transitional phenomena. In Through paediatrics to psychoanalysis: Collected papers (Chapter XVIII, pp. 229-242). New York: Brunner Mazel Publishers.

Winnicott, D. (1958). Child analysis in the latency period. In M. Khan (Ed.), The maturational processes and the facilitating environment., Int. Psycho-Analytical Library, 64, 1-276. 